\title{
Acción colectiva de las mujeres y derechos humanos en México: movilizando el dolor en medio del conflicto armado
}

\author{
Collective action of women and human rights in Mexico: mobilizing \\ pain amid the armed conflict \\ Ação coletiva das mulheres e direitos humanos no México: mobilizando \\ a dor no meio do conflito armado
}

\section{SANDRA HiNCAPIÉ ${ }^{*}$}

FeCHA DE RECEPCIÓN: 7 DE NOVIEMBRE de 2016. FeCHA DE ACEPTACIÓN: 22 DE MARZO DE 2017

Para citar este artículo: Hincapié, S. (2017). Acción colectiva de las mujeres y derechos humanos en México: movilizando el dolor en medio del conflicto armado. Estudios Socio-Jurídicos, 19(2), 97-127. Doi: xxxxxx

\section{RESUMEN}

Este artículo explica cómo afecta la actual crisis de derechos humanos a las mujeres en México. Se argumenta que este contexto afecta a las mujeres en dos sentidos diferentes: por un lado, las mujeres se han convertido en objetivo de organizaciones criminales, al utilizarlas como medio de rentas y arma de guerra. Por otro lado, en este mismo escenario se ha desarrollado un proceso creciente de acción colectiva por parte de mujeres que se han apropiado del lenguaje de los derechos humanos como marco de identidad y recurso de movilización, exigiendo justicia, promoviendo la rendición de cuentas y la acción efectiva de las autoridades estatales, lo cual ha contribuido a ensanchar el campo de defensa de los derechos humanos.

Palabras clave: acción colectiva, derechos humanos, crimen organizado, mujeres, México.

* Doctora en Investigación en Ciencias Sociales con mención en Ciencia Política de la FLACSO sede México. Pertenece al Sistema Nacional de Investigadora. Docente investigadora en la Unidad Académica de Ciencia Política de la Universidad Autónoma de Zacatecas. Correo electrónico: sandramiled@gmail.com 


\section{ABSTRACT}

This article explains how the current human rights crisis affects women in Mexico. It is argued that this context affects women in two different ways: on the one hand, women have become targets of criminal organizations, using them as a means of income and a weapon of war. On the other hand, in this same scenario, a growing process of collective action has been developed by women who have adopted the language of human rights as a frame of identity and mobilization resource, claiming justice, promoting accountability and Effective action by the state authorities, which has contributed to broadening the field of defense of human rights.

Key words: collective action, human rights, organized crime, women, Mexico

\section{RESUMO}

Este artigo explica como afeta a atual crise de direitos humanos às mulheres no México. Argumenta-se que este contexto afeta às mulheres em dois sentidos diferentes: por um lado, as mulheres se têm convertido em objetivo de organizações criminais, ao utilizá-las como meio de rendas e arma de guerra. Por outro lado, neste mesmo cenário se tem desenvolvido um processo crescente de ação coletiva por parte das mulheres que se têm apropriado da linguagem dos direitos humanos como marco de identidade e recurso de mobilização, exigindo justiça, promovendo a rendição de contas e a ação efetiva das autoridades estatais, o que tem contribuído a ensanchar o campo de defensa dos direitos humanos.

Palavras-chave: ação coletiva, direitos humanos, crime organizado, mulheres, México. 


\section{Introducción}

El 19 de octubre de 2016 en Latinoamérica y el 8 de marzo de 2017 en diferentes ciudades del mundo, cientos de mujeres marcharon bajo las consignas Ni una menos y Nosotras paramos para hacer visible lo invisible, exigir la eliminación de la discriminación, la violencia y las desigualdades de género (Sosa, 2016; ONU Mujeres, 2017). Como antecedente inmediato para el caso mexicano, el 24 de abril de 2016 con la consigna \#VivasNosQueremos mujeres se movilizaron en al menos cinco ciudades del país, denunciando las graves violaciones a los derechos humanos de las mujeres y el fracaso del Estado para proteger su vida e integridad, expresado en las altas tasas de feminicidios y desapariciones en todo el país (García \& Padilla, 2016).

En México se han desarrollado extensos y profundos análisis sobre la violencia de género en el marco de la estructura patriarcal, donde las mujeres son objeto de múltiples y variados sometimientos y vejámenes por su pertenencia de género (Russell \& Radford, 2006; Álvarez \& Pérez, 2010; Cobo, 2011; Castañeda, Ravelo \& Pérez, 2013). Sin embargo, ni las investigaciones sobre violencia de género, ni los estudios sobre la crisis de derechos humanos en México (Méndez, 2014; Amnesty International, 2015; Comisión Interamericana de Derechos Humanos, 2015; Open Society, 2016) se han preguntado: ¿cómo afecta la actual crisis de derechos humanos a las mujeres en México?

En este artículo argumento que la actual crisis de derechos humanos, en el contexto de conflicto armado por la expansión de organizaciones criminales y la respuesta estatal, ha afectado a las mujeres en dos sentidos diferenciados: por un lado, las mujeres están sufriendo violencia directa al convertirse en objetivo del accionar criminal, utilizadas como armas de guerra y medio de rentas. Por otro lado, en este mismo escenario se ha configurado un ciclo de movilización y acción colectiva por parte de las mujeres víctimas directas e indirectas del conflicto armado en las regiones y localidades. Estas mujeres se están apropiando del lenguaje de derechos humanos como marco de identidad para la acción colectiva y recurso de movilización; en la exigencia de justicia están creando capacidades para la defensa de los derechos humanos, propiciando la rendición de cuentas por parte de los gobiernos locales y federal, creando organizaciones 
y redes para la búsqueda de desaparecidas. Dicha acción colectiva por parte de las mujeres ha conducido a un ensanchamiento del campo de defensa de los derechos humanos en el territorio nacional y una mayor socialización de estrategias de movilización en amplios colectivos sociales.

Metodológicamente, aunque las fuentes secundarias se destacan como respaldo de la información presentada, el artículo está basado en un amplio trabajo de campo desarrollado entre 2010 y 2016 en diferentes regiones y localidades del país, con observaciones directas y entrevistas a funcionarios públicos, víctimas y activistas de derechos humanos que ha sido utilizadas en diversas publicaciones con otros énfasis.

El artículo está organizado de la siguiente manera: en la primera parte defino los derechos humanos, su relación con la movilización y la acción colectiva como factor esencial de socialización y presión para el cambio del comportamiento estatal; en la segunda parte analizo el aumento de la violencia contras las mujeres en el contexto de expansión del crimen organizado en México; la tercera parte está dedicada a examinar la acción colectiva de mujeres "comunes" en escenarios locales y regionales frente a las graves violaciones de derechos humanos, la construcción de sus marcos de identidad y recursos de movilización, para finalizar con unas conclusiones.

\section{Derechos humanos y marcos de acción colectiva}

Las investigaciones sobre derechos humanos abarcan muy diversas disciplinas como el derecho, la ciencia política, la filosofía, las relaciones internacionales y la sociología, desde las cuales son estudiados a partir de diversos marcos interpretativos (Risse, Ropp \& Sikkink, 1999; Landman, 2006; Simmons, 2009; Stammers, 2009; Sen, 2010; Vásquez \& Estévez, 2010; Risse, Ropp \& Sikkink, 2013; Sikkink, 2014). Reconociendo esta diversidad de perspectivas, entiendo los derechos humanos como horizontes normativos y proposiciones éticas que sirven de marco tanto para la acción estatal, al traducirse en mecanismos que genera expectativas y posibilidad de exigibilidad a través de los dispositivos jurídicos establecidos nacional e internacionalmente, como también para la acción colectiva de personas y colectivos sociales como recursos de movilización 
(Hincapié, 2015). Estos tres aspectos definitorios de los derechos humanos se corresponden con planos de incidencia diferenciados (ver tabla 1).

Tabla 1. Derechos Humanos: aspectos definitorios y planos de acción

\begin{tabular}{|l|l|}
\hline \multicolumn{1}{|c|}{ Aspectos definitorios } & Planos de Acción \\
\hline $\begin{array}{l}\text { Repertorios o discursos que defienden un conjunto de principios o } \\
\text { proposiciones éticas (que no son inmutables o incontrovertibles) }\end{array}$ & Ideas \\
\hline $\begin{array}{l}\text { En los Estados e Instituciones de carácter internacional son mecanismos } \\
\text { concretos que posibilitan su exigencia legal }\end{array}$ & Institucional \\
\hline $\begin{array}{l}\text { Recursos de movilización para la reivindicación de diversos objetivos } \\
\text { (fortalecimiento, eficacia y cumplimiento, inclusión de otros grupos y/o } \\
\text { nuevas exigencias, transformación). }\end{array}$ & Acción colectiva \\
\hline
\end{tabular}

Fuente: Elaboración propia.

El origen de los derechos está íntimamente relacionado con la historia de los procesos de negociación y luchas por la inclusión y la obediencia al orden estatal; las posibilidades de reconocimiento por la pertenencia a una comunidad política y la expansión de titularidades asociadas, han dado respuestas concretas a los cuestionamientos de distribución y al para qué de la organización estatal (Tilly, 2004; Hunt, 2009). Durante todo el siglo XX los Estados iniciaron procesos de institucionalización de los derechos humanos, en la medida que fueron reconocidos y empezaron a ser parte de sus lógicas institucionales, creando diversos mecanismos para su protección y garantía (Stammers, 2009). En las últimas décadas, los derechos fundamentales en particular y los derechos humanos en general, se han convertido en el centro de múltiples disputas, reforzadas por los procesos de mundialización, en tanto la internacionalización de los derechos humanos ha servido para fortalecer los recursos de movilización en los escenarios estatales, para acceder a formas de distribución y reconocimiento más amplias e incluso para la exigencia de corresponsabilidades entre los Estados (Tilly \& Wood, 2010; Tsutsui, Whitlinger, \& Alwyn, 2012).

La socialización del régimen internacional de los derechos humanos y las redes de presión transnacional han sido hasta ahora los enfoques predominantes en las investigaciones sobre acción colectiva y derechos humanos, poniendo en el centro del análisis las dinámicas internacionales de 
reivindicación de derechos humanos y la capacidad de la movilización para influir en el cambio del comportamiento estatal (Keck \& Sikkink, 2000; Risse et ál., 1999-, Risse et ál., 2013). Sin embargo, investigaciones recientes han hecho énfasis en la necesidad de explicar los procesos de movilización en derechos humanos al interior de los Estados, las formas de articulación en los contextos sociales y políticos específicos que enmarcan la localización de las acciones colectivas (López \& Hincapié, 2015).

De acuerdo con lo anterior y desde la perspectiva de la movilización de recursos y contienda política, entiendo la acción colectiva y la movilización como juegos estratégicos de relaciones de poder, en relación con el contexto político que incentiva o desincentiva la acción (McAdam, McCarthy \& Zald, 2006; Tarrow, 2009). Desde estas teorías, se analizan los repertorios de acción colectiva, que hacen referencia al uso combinado y sostenido de acciones políticas como reuniones, mítines, reuniones públicas, declaraciones, creación de redes y coaliciones asociados a los fines específicos de la movilización (Tilly \& Wood, 2010). Del mismo modo, el escenario de disputa o la "dialéctica de confrontación", entendido como las reacciones y contrapesos del entorno político que puede determinar estructuras de oportunidad que puede estimular la participación al afectar las expectativas de éxito o fracaso de las acciones colectivas (Tarrow, 2009).

En las investigaciones sobre acciones colectivas en derechos humanos al interior de los Estados, el análisis de la contienda política ha sido determinante en las explicaciones sobre la configuración de los campos de defensa de los derechos humanos por parte de organizaciones y agentes especializados (López \& Hincapié, 2015; Hincapié \& López, 2016). Sin embargo, los marcos de identidad, intenciones y emociones cobran centralidad en el estudio de acciones colectivas en amplios colectivos sociales no especializados cuya movilización, por lo general, está vinculada con procesos de victimización, o solidaridad con las víctimas, en escenarios de graves violaciones de derechos humanos.

Por esta razón, el análisis de acciones colectivas en derechos humanos por parte de agentes no especializados no se limita a las consideraciones sobre cálculos estratégicos respecto a la correlación de fuerzas y estructuras de oportunidad por parte de los actores involucrados, sino también, incluye los marcos de identidad, intensiones y emociones de los participantes, 
como parte fundamental en la construcción de la acción política (Jasper, 2012; Jasper, 2014).

En este caso particular me interesa analizar la configuración de acciones colectivas por parte de mujeres, como agentes no especializadas en el campo de defensa de los derechos humanos y que han configurado un ciclo de movilización, como un momento de intensificación y auge de la acción colectiva (Tarrow, 2009), generado como respuesta al escenario de conflicto armado por el que atraviesa México. Para ello, vinculo los marcos de identidad, intensiones y emociones que motivan la participación y la sostienen, consolidando acciones colectivas a través del tiempo, con los repertorios y estrategias de presión propios de las estructuras de oportunidad para la movilización de recursos (ver tabla 2).

Tabla 2. Dimensiones de análisis de la acción colectiva por los derechos humanos

\begin{tabular}{|l|l|}
\hline \multicolumn{1}{|c|}{ Dimensión } & \multicolumn{1}{c|}{ Características } \\
\hline Marcos de identidad & $\begin{array}{l}\text { Reconocimiento de características comunes que permiten crear lazos } \\
\text { entre los participantes de la acción colectiva }\end{array}$ \\
\hline Emociones & Lealtades u orientaciones afectivas que motivan la participación \\
\hline Intensiones & $\begin{array}{l}\text { Relación reflexiva entre identidad y emoción como posibilitadores de } \\
\text { la acción }\end{array}$ \\
\hline $\begin{array}{l}\text { Repertorios de } \\
\text { confrontación }\end{array}$ & Demandas compartidas y socializadas por los actores colectivos \\
\hline $\begin{array}{l}\text { Estrategias de presión } \\
\text { Prácticas llevadas a cabo para difundir y sostener las demandas } \\
\text { colectivas }\end{array}$ \\
\hline $\begin{array}{l}\text { Resultados de la } \\
\text { acción colectiva }\end{array}$ & $\begin{array}{l}\text { Efecto tanto interno a la acción colectiva como externo a la } \\
\text { movilización resultado de la presión ejercida }\end{array}$ \\
\hline
\end{tabular}

Fuente: Elaboración propia

\section{Violencia contra las mujeres en el contexto de expansión del crimen organizado en México}

Desde la década de los noventa en la ciencia política y las relaciones internacionales se ha venido desarrollando una amplia variedad de investigaciones sobre guerras y conflictos armados internos en todo el mundo, 
los cuales han puesto en cuestión los fundamentos teóricos y jurídicos de las guerras enclavados en las dinámicas bélicas convencionales. El estudio de estas "nuevas guerras" han iluminado diversos aspectos de las confrontaciones violentas ofreciendo tipologías, más o menos integradoras, a partir del análisis de diferentes dimensiones como son las motivaciones, objetivos, microdinámicas e intensidad de la confrontación, entre otras, que difieren y cuestionan las definiciones clásicas de las guerras civiles en la medida que no se circunscriben a una confrontación extrema para la conquista del poder político (Van Creveld, 1991; David, 1997; Shaw, 1999; Waldmann \& Reinares, 1999; Kaldor, 2001; Kalyvas, 2001; Kalyvas, 2003, Kalyvas, 2006; Fearon \& Laitin, 2003; Sambanis, 2004; Eriksson E Wallensteen, 2004; Collier \& Hoeffler, 2004; Dorff, 2005; Hegre $\mathcal{E}$ Sambanis, 2006; Bates, 2008).

A partir de estas investigaciones el contexto mexicano actual puede ser caracterizado como un conflicto armado interno e incluso algunos autores han llegado a considerarlo como el escenario de una guerra civil (Waldmann, 2012; Schelder, 2016). Más allá de la polémica sobre la denominación apropiada para los conflictos armados protagonizados por organizaciones criminales y la subsecuente respuesta estatal en México, es innegable que durante los últimos diez años dichas organizaciones se han transformado de manera radical mediante procesos de fragmentación, competitividad, expansión de organizaciones y diversificación de actividades, que las han llevado a tener un mayor control territorial, incrementando los niveles de violencia y degradación de la seguridad pública ( Corcoran, 2011; Guerrero, 2011; Finklea et ál., 2011; Grayson E Logan, 2012; Beittel, 2015).

Los cambios en el comportamiento criminal han traído como consecuencia un incremento en graves violaciones de los derechos humanos contra las mujeres, las cuales se han convertido en objetivo y fuente de financiamiento de las organizaciones criminales a través de la trata de personas, prostitución, venta de niñas, pornografía y tráfico de drogas, entre otras. Del mismo modo, la expansión en el control territorial de las organizaciones criminales y su connivencia con agentes estatales, han contribuido a exacerbar la violencia de género como patrón social ampliamente extendido favoreciendo su impunidad (Comité para la eliminación de la discriminación contra la mujer - CEDAW, 2012). 
Hasta ahora el centro de los debates sobre violencia de género en México ha sido el feminicidio como la manifestación más letal de la violencia contra las mujeres (Segato, 2006; Lagarde, 2011; Sagot \& Carcedo, 2011). En la Ley General de Acceso de las Mujeres a una Vida Libre de Violencia el feminicidio es definido como:

Artículo 6. [...]la forma extrema de violencia de género contra las mujeres producto de la violación de sus derechos humanos, en los ámbitos público y privado, conformada por el conjunto de conductas misóginas que pueden conllevar impunidad social y del Estado y puede culminar en homicidio y otras formas de muerte violenta de mujeres (2007).

Es muy importante subrayar que estos informes sobre feminicidios no se han analizado a la luz de los cambios en el contexto por la actuación de organizaciones criminales; sin embargo, las cifras que proporcionan son contundentes. Como observamos en el Gráfico 1, a partir de datos oficiales presentados en el informe La violencia feminicida en México, aproximaciones y tendencias 1984-2014 (Echarri, 2016), se advierte un crecimiento significativo y constante de los asesinatos a mujeres en México a partir de 2007. El incremento ha sido tal que entre el año 2007 (1087 homicidios) y el año 2012 (2761 homicidios) hubo un aumento del $154 \%$, de los homicidios contra mujeres en todo el país.

El aumento significativo en los asesinatos de mujeres se relaciona con el contexto de conflictos armado si consideramos el aumento de estos asesinatos en la vía pública. Tal y como se presenta en el gráfico 2 , históricamente eran mayores los homicidios contra las mujeres perpetrados en el ámbito privado. A partir del 2007, no obstante, hay un crecimiento de los homicidios en la vía pública que transforma la tendencia prevaleciente a partir de 2009 (sin que esto signifique una disminución de la violencia en el ámbito privado), llegando a su punto más alto en 2012. Estas cifras se corresponden con las dinámicas de los conflictos armados relacionadas con la expansión de organizaciones criminales a partir del 2007, sus disputas y enfrentamientos con las fuerzas de seguridad estatal, tal y como ha sido presentada en diversos informes (Escalante, 2011; Berber, 2016). 


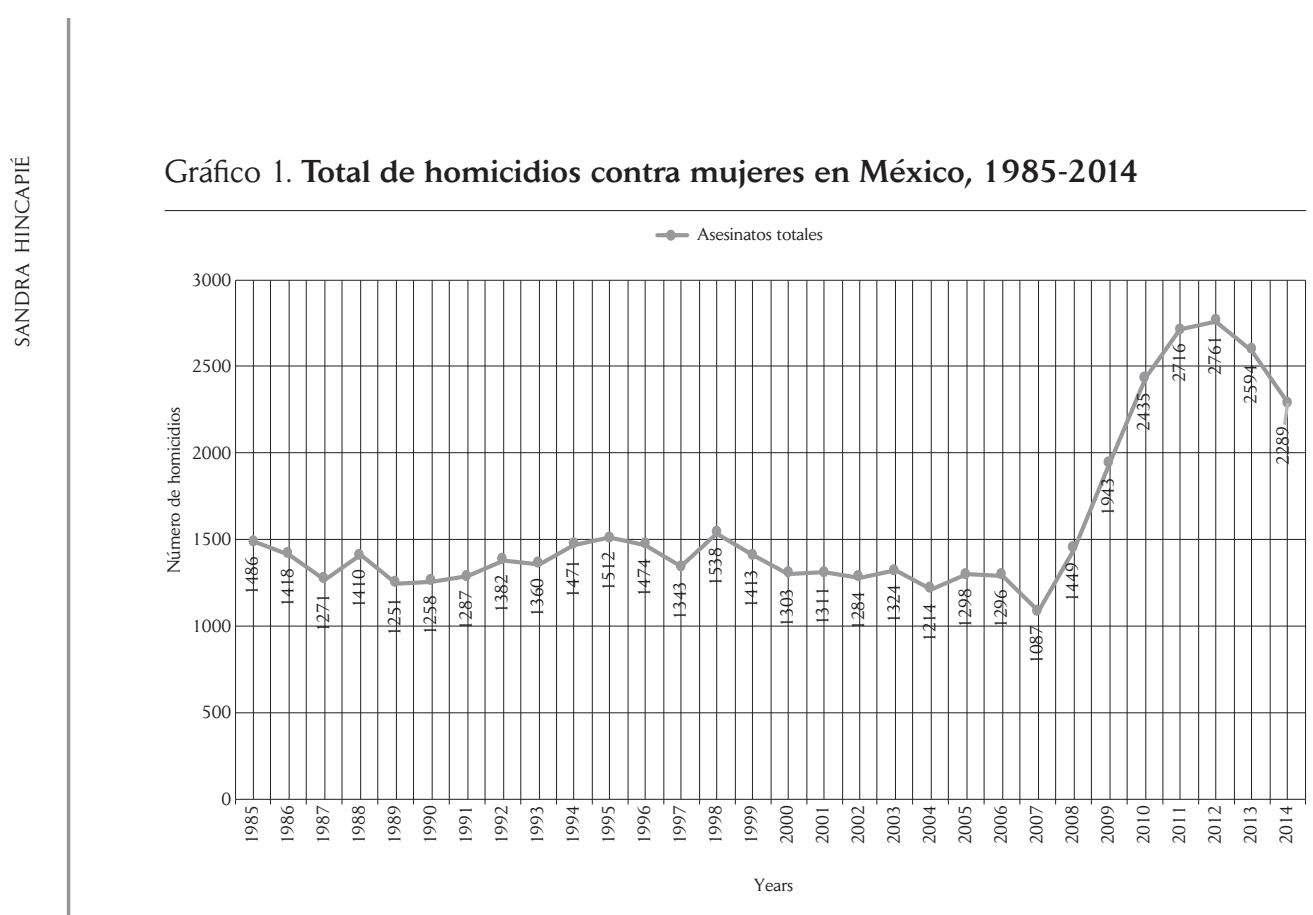

Fuente: Elaboración propia con datos de SEGOB, INMUJERES \& ONU MUJERES

Gráfico 2. Total de mujeres asesinadas por lugar de los hechos en México, 1999-2014

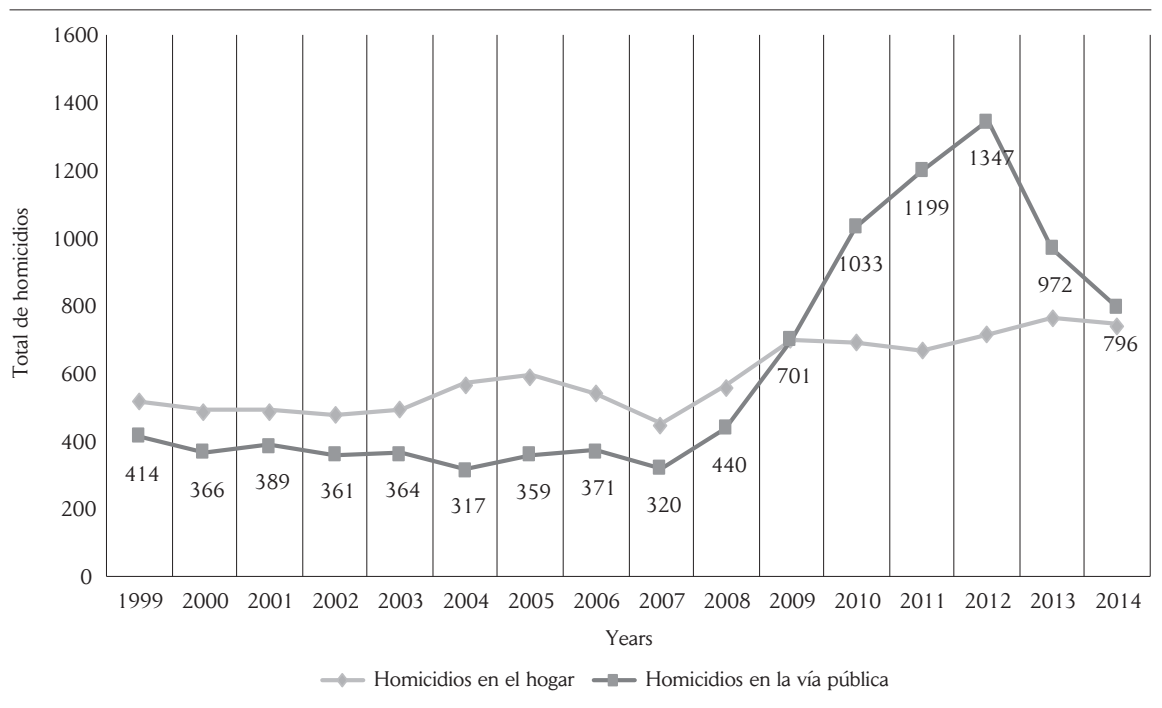

Fuente: Elaboración propia con datos de SEGOB, INMUJERES \& ONU MUJERES 
Esta relación es aún más clara si apreciamos el gráfico 3. En los Estados fronterizos de Tamaulipas y Chiapas el aumento de los asesinatos a mujeres llega a tasas superiores al 340\%. Además de Tamaulipas, casi todos los estados de la frontera norte presentan los mayores incrementos del país, como vemos en Coahuila, Chihuahua, Sinaloa y Baja California. También encontramos incrementos sustanciales en Estados del interior del país como Hidalgo y Morelos; en todos los casos, los Estados incluidos en la gráfica cuentan con una activa presencia de organizaciones criminales.

Gráfico 3. Estados con mayores porcentajes de incremento de asesinatos de mujeres entre el 2007 y 2014 en México

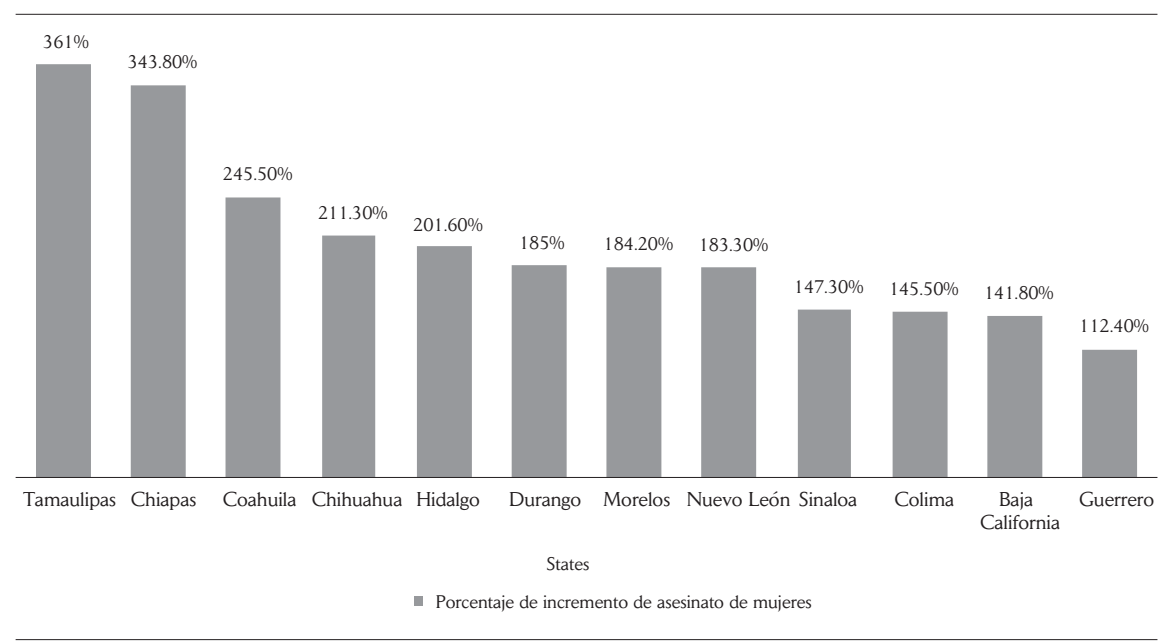

Fuente: Elaboración propia con datos de SEGOB, INMUJERES \& ONU MUJERES.

Las cifras sobre feminicidios ofrecidas por las autoridades estatales hacen evidente la gravedad de la situación de los derechos humanos de las mujeres en México, así como los cambios incrementales a partir del 2007, que se relacionan con los cambios en el contexto por los conflictos armados debidos a la expansión y consolidación de las organizaciones criminales.

Investigaciones sobre feminicidios en Ciudad Juárez, realizadas en el Centro de Investigaciones y Estudios Superiores en Antropología Social (CIESAS) por Patricia Ravelo, han identificado un patrón sistemático en los cuerpos de las mujeres y niñas asesinadas, los cuales coinciden en presentar cortes y mutilaciones propios de la "pornografía sádica". Según 
la investigadora, las marcas encontradas en los cuerpos corresponden a lesiones propias de tortura y sexo violento, utilizadas en la "industria criminal transnacional" donde se han insertado las organizaciones del crimen organizado que operan en México (Excelsior, 2015).

De acuerdo con lo anterior, los feminicidios son el último eslabón en una cadena de vejaciones que en muchos casos inician con el rapto y la desaparición forzada, el tráfico de personas, el sometimiento a tortura y esclavitud sexual para, finalmente, terminar siendo asesinadas frente a cámaras que registran los detalles. Todo un engranaje de explotación basado en la violencia de género al cual están siendo sometidas mujeres y niñas en territorio mexicano por parte de organizaciones armadas.

\subsection{Desaparición, trata de personas y esclavitud sexual: mujeres y niñas como objetivo criminal}

México es un país tanto de origen como de tránsito y destino de mujeres y niñas víctimas del delito de trata de personas. Con la expansión y diversificación de actividades del crimen organizado en México, la trata de personas con fines de explotación sexual ha pasado a ser una de sus principales fuentes de financiación. En ese contexto, mujeres y niñas se han convertido en objetivo de las actividades criminales en todos los Estados del país. En los últimos años, se ha llamado la atención particularmente sobre la situación de las mujeres y niñas migrantes en tránsito hacia Estados Unidos que han sido objeto de la trata de personas, en su gran mayoría migrantes ilegales provenientes de Centro y Sudamérica, aunque mujeres de Europa del Este, Asia y África también han sido identificadas en México (Departament of State, 2016).

Se ha señalado que las zonas turísticas del país, así como las ciudades de la frontera norte, son considerados lugares de destino de mujeres y niñas víctimas de la trata, con fines de explotación y esclavitud sexual. En un informe presentado en 2014, la Subprocuraduría Especializada en Investigación de Delincuencia Organizada (SEIDO) de la Procuraduría General de la República (PGR), logró determinar cómo se articula una red de pequeñas organizaciones familiares dedicada a la trata de personas en el Estado Tlaxcala, con grandes organizaciones criminales como los Zetas, 
Guerreros Unidos y el Cártel del Golfo, quienes controlan corredores que utilizan para diferentes fines a lo largo y ancho del país (Flores, 2014).

Evangelina Hernández ha documentado a partir de diversas fuentes y testimonios de lugares como Tenancingo, municipio de Tlaxcala, que la trata de personas representa una de las más importantes fuentes de sostenimiento económico de las organizaciones criminales (Hernández, 2015). Precisamente, a partir del caso de Tlaxcala, se advierten las transformaciones en las dinámicas de la trata de personas, que ahora articulan los clanes familiares, dedicados tradicionalmente al "enganche" y "rapto" de mujeres para su explotación sexual, con las grandes organizaciones criminales. En ese sentido, la trata de mujeres y niñas ha sufrido una expansión y sofisticación, que se traslapa con los negocios de drogas y migrantes ilegales en rutas controladas por las organizaciones criminales (Gurney, 2014).

El traslape, sofisticación y evolución para diversos fines de la trata de mujeres y niñas, se corresponde con la diversificación de actividades económicas del crimen organizado en México. La relación entre el contexto de violencia a partir de la expansión del crimen organizado y el aumento en la trata de mujeres y niñas ha sido señalada en los informes del gobierno federal. La Comisión Intersecretarial ${ }^{1}$ en su informe anual de 2013, señaló que "se ha incrementado exponencialmente" la trata de personas en el país "a consecuencia de la delincuencia organizada" (Comisión Intersecretarial, 2014, p. 11). En el mismo sentido, el Programa Nacional para Prevenir, Sancionar y Erradicar los Delitos en Materia de Trata de Personas y para la Protección y Asistencia a las Víctimas de estos Delitos 2014-2018 señala en su diagnóstico sobre la trata de personas que:

[...] la delincuencia organizada y los modelos de lucha contra el crimen en el pasado incrementaron los niveles de violencia y multiplicaron las formas en que la criminalidad ha desplegado sus efectos sobre las capas más vulnerables de la población. Las modalidades delictivas han

1 La Comisión Intersecretarial para prevenir, sancionar y erradicar los delitos en materia de trata de personas, es la instancia encargada de definir y coordinar la implementación de una política de Estado en materia de trata de personas, prevista en la Ley General para Prevenir Sancionar y Erradicar los Delitos en Materia de Trata de Personas y para la Protección y Asistencia a las Víctimas de estos Delitos (Artículo 84). 
aumentado y mutado constantemente, resultando en una expansión de áreas de operación y de diversificación de actividades delictivas, colocando a la trata de personas en los primeros lugares de impacto social negativo, por las ganancias ilícitas que genera, convirtiéndola así en una grave amenaza a la mayoría de la población.

Los grupos delincuenciales vinculados a la trata de personas se asocian de tal manera que abarcan en la comisión de sus actividades, la captación, el transporte y la gestión de la explotación, ligándose a diversos grupos locales e incluso a otros del ámbito internacional, generándose con ello la delincuencia organizada trasnacional, que diversifica los puntos de enganche, tránsito y destino (Comisión Intersecretarial, 2014).

Hasta aquí podemos establecer la razón de ser entre las diferentes violaciones a los derechos humanos de las mujeres, la desaparición forzada asociada a la trata y la esclavitud sexual, que incluye la pornografía sádica y culmina en muchas ocasiones en feminicidio, al ser actividades lucrativas para las organizaciones criminales extendidas por todo el territorio nacional.

Unido a lo anterior, el Estado mexicano ha sido denunciado por hacer de la tortura una práctica sistemática para lograr confesiones de detenidos acusados de pertenecer a organizaciones criminales (Méndez, 2014; Amnesty International, 2015; Comisión IDH, 2015; Open Society, 2016). Las mujeres no han escapado a estas prácticas de tortura, las cuales llegan incluso a ser divulgadas por medio de videos en las redes sociales (Martínez, 2016a; Flores \& Reyes, 2016).

Además de la tortura, las mujeres arrestadas por presuntos vínculos con organizaciones criminales están siendo sometidas a violencia sexual por parte de la policía y de las diversas fuerzas armadas. Después de entrevistar a cien mujeres presas en diferentes cárceles de México, acusadas de pertenecer a organizaciones criminales, Amnistía Internacional ha podido establecer que la violencia sexual es una "práctica habitual" de las autoridades estatales (policías, marinos o militares) durante el arresto y el interrogatorio, para conseguir confesiones por parte de las mujeres (Amnesty International, 2016)².

2 Metodológicamente, el grueso de la información que soporta los resultados del informe de investigación realizado por Amnistía Intenacional, se basa en un cuestionario realizado por 
De acuerdo con lo anterior, en el contexto de conflicto armado, como resultado de la expansión de organizaciones criminales en el territorio mexicano y la persecución de las autoridades estatales, las mujeres están siendo sometidas a una alta violencia sexual por todas las partes enfrentadas y utilizadas como arma de guerra.

Aunque los diagnósticos realizados por las propias autoridades estatales sean claros en señalar la gravedad de la situación de los derechos humanos de las mujeres en un contexto de actuación de organizaciones criminales, las autoridades se resisten a decretar medidas de emergencia para proteger las mujeres y niñas en el territorio nacional.

De todas las disposiciones y medidas tomadas hasta ahora, la herramienta más importante para intervenir en graves situaciones de violencia contra las mujeres ha sido la Alerta de Violencia de Género (AVG). Esta medida hace parte de los mecanismos considerados en la Ley General de Acceso de las Mujeres a una Vida Libre de Violencia (LGAMVLV), y fue diseñada para la intervención de las autoridades federales cuando los gobiernos estatales no hubiesen actuado en situaciones graves de violencia contra las mujeres.

Las organizaciones de la sociedad civil desde 2008 presentaron peticiones de declaratoria de la Alerta de Género en diecisiete estados dada la gravedad de la situación por el incremento sustancial de los feminicidios. Hasta el 2013, ninguna Alerta había sido aprobada razón por la cual las diversas organizaciones agrupadas en la red del Observatorio Ciudadano Nacional del Feminicidio solicitaron la reforma a la Ley General de Acceso y, específicamente, al reglamento establecido para decretar el mecanismo de Alerta, dada su infectividad y las dificultades procedimentales para acceder a sus beneficios.

El hecho de que no se hubiera declarado ninguna Alerta de Violencia de Género entre 2008 y 2014, a pesar del incremento sustancial de los feminicidios, da cuenta de las omisiones del Estado para garantizar la vida e integridad de mujeres y niñas, en el contexto de violencia por la actuación del crimen organizado. Gracias a la insistente acción colectiva de las mujeres para denunciar los hechos de violencia en las localidades,

escrito a sesenta y seis mujeres y en entrevistas en profundidad con treinta y cuatro mujeres, llevadas a cabo en visitas a tres cárceles diferentes. 
el 28 de julio 2015 por primera vez fue declarada la Alerta de Género en once municipios del Estado de México; dos semanas después, el 10 de agosto de 2015, fue decretada la Alerta de Violencia de Género en ocho municipios del Estado de Morelos (Rosagel, 2016). En ambos casos, las declaratorias de alerta fueron posibles después de largos procesos y demandas interpuestas por organizaciones sociales (Martínez, 2016; Román, 2015).

Aunque el 27 de junio de 2016 fue activada la Alerta de Violencia de Género para catorce municipios del Estado de Michoacán, diversas solicitudes para declarar la Alerta de Violencia de Género en Estados como Sinaloa y Guanajuato han sido negadas. Las activistas han señalado que las autoridades "obstaculizan la Alerta de Violencia de Género, como si se tratara de una agresión contra los gobiernos" (Villela, 2016). A pesar de las cifras de feminicidios y el riesgo inminente que sufren las mujeres en estados como Tamaulipas, documentados por las mismas autoridades estatales, no se ha declarado ninguna Alerta de Violencia de Género en la entidad, ni creado algún otro mecanismo de emergencia que pueda intervenir para proteger la vida e integridad de las mujeres, así como garantizar sus derechos humanos.

\section{Mujeres en movimiento: de víctimas a activistas como respuesta a la crisis de derechos humanos}

La acción colectiva de las mujeres para denunciar la violencia de género en México ha sido fundamental para dar visibilidad a nivel internacional a la grave situación de violaciones a los derechos humanos y presionar por cambios en el comportamiento estatal. El caso paradigmático de movilización y acción colectiva de las mujeres, como primer ciclo de movilización en torno a los derechos humanos por parte de las mujeres y antecedente inmediato de la actual crisis de derechos humanos, fue la movilización desarrollada alrededor de Ciudad Juárez.

En esta ciudad fronteriza al norte del país, desde mediados de la década de los noventa las mujeres empezaron a organizarse en el entorno local para denunciar los asesinatos sistemáticos de mujeres, sin encontrar 
ninguna respuesta efectiva de las autoridades oficiales ${ }^{3}$. A partir del 2001, especialmente después del trágico suceso del Campo Algodonero ${ }^{4}$, la acción colectiva de las mujeres en Ciudad Juárez empezó a tener mayor visibilidad internacional. Fueron creadas organizaciones de víctimas las cuales lograron posicionar el debate sobre la situación en la ciudad a nivel nacional e internacional. La creación de redes de apoyo transnacionales, el pronunciamiento y elaboración de informes sobre Ciudad Juárez por parte de diversas organizaciones internacionales como la Comisión Interamericana de Derechos Humanos y Amnistía Internacional, llevaron a un paulatino reconocimiento gubernamental y a la implementación de diversas medidas (Martín, Fernández \& Villarreal, 2008; Aikin, 2011; Anaya, 2012).

La respuesta estatal a la presión ejercida por la acción colectiva de las mujeres, iniciada en Ciudad Juárez, llevó a la creación del Instituto Nacional de las Mujeres (INMUJERES) en 2003 y en 2007 la promulgación de la Ley General de Acceso de las Mujeres a una Vida Libre de Violencia (LGAMVLV), unida a la reforma del Código Federal de Procedimientos Penales donde se incluyó el delito de feminicidio.

A pesar del éxito en la acción colectiva transnacional, a partir del 2007 se agravaron las violaciones a los derechos humanos de las mujeres debido a los cambios en el contexto nacional ${ }^{5}$. En este nuevo escenario de violaciones masivas a los derechos humanos de las mujeres, se configuró un segundo ciclo de movilización y acción colectiva de las mujeres en escenarios locales y regionales, el cual está siendo decisivo para hacer

3 El entonces gobernador de Chihuahua minimizó e incluso justificó los hechos ocurridos aduciendo un comportamiento indebido de las mujeres asesinadas, lo que llevó a la CNDH a emitir la Recomendación 44/98.

4 En 2001 se hallaron los cuerpos de ocho mujeres en una zona periférica de Ciudad Juárez denominada Campo Algodonero, un caso que fue seguido por la Red de Mujeres de Ciudad Juárez y el acompañamiento del Centro para el Desarrollo Integral de la Mujer con el objetivo de presentar una demanda ante la Comisión Interamericana de Derechos Humanos en el 2002 (la cual fue aceptada en 2005 y finalmente emitida condena contra el Estado en el año 2009). En la sentencia, la Corte IDH reconoce que los asesinatos de estas mujeres se inscribían en un contexto de violencia e impunidad de violencia de género que impera en Ciudad Juárez, obligando al Estado mexicano a tomar medidas especiales frente a este fenómeno (Corte Interamericana de Derechos Humanos, 2009).

5 En otro texto hemos destacado cómo en el contexto actual de crisis de derechos humanos las ONG locales y regionales han tenido un decisivo papel para la denuncia de la crisis humanitaria a nivel nacional e internacional (Hincapié E López, 2016). 
visibles, ante la opinión pública nacional e internacional, las graves violaciones y la crisis de derechos humanos que se viven en México. Dicha acción colectiva de madres, esposas y víctimas directas e indirectas, que fueron arrancadas de su cotidianidad por los hechos violentos, están denunciando y exigiendo justicia, pero también creando organizaciones y tejiendo redes de apoyo fundamentales para la construcción de paz y el empoderamiento de las mujeres como defensoras de sus derechos, pasando de víctimas a activistas de derechos humanos.

En la siguiente tabla (ver tabla 3) encontramos ejemplos relevantes de acción colectiva de mujeres en distintas ciudades y localidades de México. Como veremos a continuación, sin excepción, todas estas iniciativas surgieron como reacción de mujeres comunes ante un hecho violento. Sin antecedentes o trayectorias de activismo, cuando una mujer expuso

Tabla 3. Iniciativas locales relevantes de acción colectiva de mujeres frente a la crisis de derechos humanos en el contexto de conflicto armado

\begin{tabular}{|c|c|c|c|}
\hline Año & Nombre & Ciudad & Fundadoras \\
\hline 2001 & Nuestras Hijas de Regreso a Casa, A. C. & $\begin{array}{l}\text { Ciudad } \\
\text { Juárez }\end{array}$ & $\begin{array}{l}\text { Marisela Ortiz y Norma } \\
\text { Andrade }\end{array}$ \\
\hline 2002 & Justicia para Nuestras Hijas, A. C. & Chihuahua & Norma Ledezma \\
\hline 2008 & Voces Unidas por la Vida & Culiacán & Alma Trinidad Camacho \\
\hline 2008 & Asociación Ciudadana contra la Impunidad & Tijuana & Cristina Palacios Roji \\
\hline 2011 & $\begin{array}{l}\text { Amores DNL. Agrupación de Mujeres } \\
\text { Organizadas por los Ejecutados, Secuestrados } \\
\text { y Desaparecidos de Nuevo León }\end{array}$ & Nuevo León & \\
\hline 2011 & Buscamos a Nuestras Hijas & Xalapa & Bárbara Ibarra \\
\hline 2011 & $\begin{array}{l}\text { Comité de Madres y Familiares con Hijas } \\
\text { Desaparecidas en Ciudad Juárez }\end{array}$ & $\begin{array}{l}\text { Ciudad } \\
\text { Juárez }\end{array}$ & $\begin{array}{l}\text { Olga Esparza y Norma } \\
\text { Laguna }\end{array}$ \\
\hline 2013 & $\begin{array}{l}\text { Comité de Familiares de Desaparecidos } \\
\text { Orizaba-Córdoba }\end{array}$ & $\begin{array}{l}\text { Orizaba- } \\
\text { Córdoba }\end{array}$ & Aracely Salcedo \\
\hline 2013 & $\begin{array}{l}\text { Familias Unidas en la Búsqueda y } \\
\text { Localización de Personas Desaparecidas, } \\
\text { Piedras Negras - Coahuila }\end{array}$ & $\begin{array}{l}\text { Piedras Negras } \\
\text { - Coahuila }\end{array}$ & $\begin{array}{l}\text { María Hortencia Rivas } \\
\text { Yolanda Vargas González }\end{array}$ \\
\hline 2014 & Colectivo Solecito & Veracruz & Lucía Díaz Genao \\
\hline 2014 & Las Rastreadoras & Sinaloa & Mirna Nereyda \\
\hline
\end{tabular}

Fuente: Elaboración propia. 
su dolor y desesperación, encontró decenas de mujeres que se reconocieron y hallaron en lenguaje de los derechos humanos la manera de traducir una emoción privada en un hecho público.

El hijo de Alma Trinidad Camacho, un estudiante de preparatoria de dieciséis años, fue asesinado en una masacre ocurrida en 2008 en Culiacán, Sinaloa, cuando un comando armado disparó de manera indiscriminada frente a un taller automotriz. Alma Trinidad exigió justicia para el caso de su hijo, hizo pancartas, plantones y marchas, se reunió con otras madres en la misma situación y crearon la organización Voces Unidas por la Vida:

Yo quise salir a la calle a protestar, a decirle a nuestra autoridades que no se está trabajando y todos se hacían de oídos sordos [...] Con todo esto me di cuenta del país en el que vivimos, ya no quise seguir, tuve miedo, tú sabes cómo se manejan las cosas en Sinaloa, porque afectas intereses, la autoridad no te protege (Manjarrés, 2013).

A pesar de las amenazas, la acción colectiva de las mujeres en Culiacán no cesó, en una de las cunas del narcotráfico en México que algunos no dudan en caracterizar como una "narcodictadura" (Tercero, 2010). Además de las marchas, denuncias y documentación de casos, las integrantes de Voces Unidas por la Vida han trabajado con las autoridades estatales en la investigación y búsqueda de desaparecidos, acopiando información de los casos e incluso haciendo excavaciones en lugares señalados por algunos informantes de manera anónima (Carrasco, 2010; Zavaleta, 2017).

En Tijuana, también en 2008, Cristina Palacios, madre de Alejandro Hodoyán, desaparecido a manos del Ejército, creó la Asociación Ciudadana Contra la Impunidad, a través de la cual se movilizaron decenas de madres y familiares víctimas de desaparición forzada y asesinatos, protagonizados por el crimen organizado en los municipios de Tijuana, Rosarito, Ensenada y Mexicali. Posteriormente, a partir de la Asociación Ciudadana Contra la Impunidad, surgió la Asociación Unidos por los Desaparecidos de Baja California la cual agrupa a los colectivos de víctimas en el Estado de Baja California (Robledo, 2015; Villarreal, 2014).

Al otro lado del país, en Xalapa, Veracruz, en junio de 2011, la hija de Bárbara Ibarra fue desaparecida y encontrada muerta tres meses después 
de manera fortuita. Durante la búsqueda Ibarra convocó a marchas y plantones que dieron origen a la asociación Busquemos a Nuestras Hijas, la cual ha liderado los procesos de denuncia sobre feminicidios y desapariciones de niñas y mujeres en Veracruz. El 20 de junio de 2011, cerca de doscientas personas marcharon, entre las que se encontraban madres de otras desaparecidas (Villareal, 2014). A través de la acción colectiva de las madres organizadas se ha exigido la actuación de las instituciones estatales para prevenir y transformar las condiciones del conflicto armado regional donde la impunidad reina:

En Veracruz se mata a las mujeres con saña; mueren después del ultraje. Las asesinan a golpe limpio. Cuelgan sus cadáveres en los árboles. El gobierno sólo ve la natilla de la mierda. Siempre, al indagar, pone su atención en la víctima, en todo lo que hizo mal para justificar los decesos. Luego viene la impunidad (León, 2016a).

Precisamente, en el municipio de Orizaba, Veracruz, el 7 de septiembre de 2012 desapareció Fernanda Rubí Salcedo Jiménez. Su madre, Aracely Salcedo, emprendió su búsqueda y en ese proceso se unió a otras madres de jóvenes desaparecidas, dando origen al Colectivo de Familias de Desaparecidos Orizaba-Córdoba en 2013. Desde entonces, han documentado casos, realizado investigaciones y búsquedas de manera independiente, marchas, plantones, denuncias públicas y acompañado a familiares. En ese recorrido las integrantes del Colectivo han sufrido todo tipo de hostigamientos y amenazas. Así lo afirma Aracely Salcedo quien ha liderado las denuncias y ha recibido medidas cautelares:

Desde que comencé la búsqueda de mi hija, se han mantenido las amenazas y hostigamientos por llamadas y vía mensajes privados en Facebook. La verdad ya no sabemos por dónde nos pegan, si del lado del Gobierno o de la delincuencia [...] Al menos veinticinco veces me han detenido en carretera, pero yo no soy una delincuente solo busco a mi niña desaparecida (Sin embargo, 2016, párr. 3-4).

Ante la inacción de los gobiernos y la connivencia con las organizaciones criminales, la iniciativa de las mujeres organizadas las ha llevado a emprender por su cuenta labores de búsqueda de cadáveres para su 
identificación. El mayor hallazgo de fosas comunes en México hasta ahora, se llevó a cabo en el puerto de Veracruz por parte del Colectivo Solecito, una agrupación de madres y hermanas de personas desaparecidas, creada en 2014 y liderada por Lucía de los Ángeles Díaz Ganeo. En agosto de 2016 estas mujeres ubicaron un terreno de fosas clandestinas donde, para marzo de 2017, se han encontrado doscientos quince cuerpos y aún queda un amplio terreno por explorar donde se sabe hay más restos óseos. Del mismo modo, el Colectivo Solecito ha promovido la rendición de cuentas de los gobiernos estatal y federal, al denunciar las omisiones para comprometerse con las investigaciones y la identificación de los cuerpos en la medida que, según Díaz: "están apostando a que todo esto se olvide [...] Todo ha sido negación, simulación por parte de ellos. Nosotros somos quienes hemos trabajado, la Fiscalía solo ha dado fe de los hallazgos, pero de ahí en fuera nada" (Rincón, 2017).

En otro lugar del país, una mujer buscaba a su hijo Víctor Manuel Guajardo Rivas, desaparecido en julio de 2013 presuntamente por parte del Grupo de Armas y Tácticas Especiales (GATE), un grupo de policías de élite formado en el Estado de Coahuila. María Hortencia Rivas Rodríguez acudió de inmediato a todas las autoridades estatales, sin encontrar ninguna respuesta o ayuda. A partir de ese momento esta mujer emprendió una búsqueda incesante que la llevó a conocer a cientos de madres que buscan igualmente a sus desaparecidos. Marchas, plantones, denuncias públicas, caminatas, manifestaciones, fueron durante años las acciones a las que apelaron para exigir alguna respuesta estatal.

Ante el incremento exponencial de desapariciones, en 2013 las madres decidieron crear la organización Familias Unidas en la Búsqueda y Localización de Personas Desaparecidas de Piedras Negras - Coahuila. A través de la organización liderada por María Hortencia Rivas y Yolanda Vargas González se brinda asesoría legal, apoyo psicológico a los familiares de desaparecidos, se difunde información y se ha construido un sistema de reacción inmediata, por medio del cual se han llegado a ubicar más de setenta personas que han sido liberadas gracias a las alertas tempranas y movilización llevada a cabo a través de la organización (Tavera, 2015).

Al norte del país, en Ciudad Juárez, en este segundo ciclo de movilización un hecho paradigmático ocurrió con el asesinato de Marisela Escobedo frente al Palacio de Gobierno en la ciudad de Chihuahua en 
2010 , hasta donde fue a exigir justicia por el feminicidio de su hija ocurrido en Ciudad Juárez en el año 2008.

La desaparición creciente de mujeres y niñas en Ciudad Juárez llevó a la conformación en marzo de 2011 del Comité de Madres y Familiares con Hijas Desaparecidas, a raíz de la movilización de las familiares de Mónica Janeth Alanis e Idali Juache, desaparecidas en 2009 y 2010 respectivamente. Son diversas las movilizaciones que han protagonizado y se han extendido por todo el Estado, para denunciar la lentitud y negligencia en las investigaciones, exigir la implementación de diversos mecanismos que garanticen la identificación adecuada de los restos y la creación de mecanismos de atención a las víctimas (Barrios, 2013; Coria, 2013).

En 2013 fue creada la Agrupación de Mujeres Organizadas por los Ejecutados, Secuestrados y Desaparecidos de Nuevo León-AMORES DNL, apoyadas en la organización no gubernamental de derechos humanos Ciudadanos en Apoyo a los Derechos Humanos A. C. (CADHAC), dirigida por la hermana Consuelo Morales. Como antecedente, en 2011 había sido creada Lucha por Amor, Verdad y Justicia (LUPA) y, al escindirse, dio origen a Fuerzas Unidas por Nuestros Desaparecidos en Nuevo León y AMORES DNL.

Gracias a la acción colectiva de las mujeres agrupadas en AMORES DNL y el acompañamiento de CADHAC, ha sido posible documentar la desaparición de personas en el Estado de Nuevo León, crear un modelo de búsqueda de la mano de las autoridades estatales e influir en la tipificación en el código penal estatal del delito de desaparición forzada cumpliendo con estándares internacionales (Cervantes, 2015; Villareal, 2014).

A todas estas iniciativas locales lideradas por mujeres, se suman a múltiples redes y colectivos como la Red de madres buscando a sus hijos y muchas otras más, las cuales cada año desde 2012 han celebrado la Marcha de la Dignidad Nacional: madres buscando a sus hijos e hijas, y buscando verdad y justicia. Años tras año mujeres han marchado por las principales ciudades del país en el mes de mayo exigiendo justicia. En mayo de 2016 la V Marcha de la Dignidad Nacional fue realizada por cientos de mujeres provenientes de todo el país, las cuales fueron acompañadas por madres centroamericanas de Guatemala, El Salvador y Honduras, además de marchas simultáneas en Veracruz, Morelos, Michoacán, Guerrero y Guanajuato (Olvera, 2016). 
En todos los casos de acción colectiva analizados, encontramos como elemento común que las mujeres, que han sido víctimas directas e indirectas de graves violaciones a los derechos humanos en el contexto de conflicto armado por el que atraviesa el país, han logrado empatizar con otras mujeres y familiares en su misma situación. Ante el desconcierto por los hechos dolorosos, la impunidad e inacción de las autoridades estatales, las mujeres han nombrado su dolor convirtiéndolo en un problema público, al encontrar en el lenguaje de los derechos humanos un marco de identidad y recurso de movilización para la acción colectiva. En la tabla 4 resumo analíticamente las principales características de éstas acciones colectivas:

Tabla 4. Características de la acción colectiva de las mujeres por los derechos humanos

\begin{tabular}{|c|c|}
\hline Dimensión & Características \\
\hline $\begin{array}{l}\text { Marcos de } \\
\text { identidad }\end{array}$ & Víctimas directas e indirectas de graves violaciones de derechos humanos \\
\hline Emociones & Dolor, impotencia, indignación, solidaridad. \\
\hline Intensiones & $\begin{array}{l}\text { Búsqueda de sus seres queridos, denuncia y exigencia de justicia, } \\
\text { acompañamiento a otras víctimas y familiares. }\end{array}$ \\
\hline $\begin{array}{l}\text { Repertorios } \\
\text { de } \\
\text { confrontación }\end{array}$ & $\begin{array}{l}\text { Exigencia de justicia y rendición de cuentas a los gobiernos y autoridades } \\
\text { locales. Reconocimiento de la crisis de derechos humanos por la que } \\
\text { atraviesa el país por parte de los gobiernos. Reclamación de participación } \\
\text { de los familiares en los sistemas de seguimiento y monitoreo a los planes y } \\
\text { programas para la búsqueda de desaparecidos. }\end{array}$ \\
\hline $\begin{array}{l}\text { Estrategias } \\
\text { de presión }\end{array}$ & $\begin{array}{l}\text { Marchas, plantones, denuncias públicas, campañas de información, caminatas, } \\
\text { manifestaciones, búsqueda independiente de desaparecidos. }\end{array}$ \\
\hline $\begin{array}{l}\text { Resultados } \\
\text { Internos }\end{array}$ & $\begin{array}{l}\text { Creación de organizaciones locales. Configuración de capacidades para } \\
\text { la asesoría legal, para el apoyo psicológico a familiares de desaparecidos, } \\
\text { construcción de sistemas de monitoreo, reacción inmediata y organización } \\
\text { de búsqueda de cuerpos e identificación de fosas comunes. Creación de } \\
\text { redes de organización de carácter nacional que agrupa a los familiares de } \\
\text { desaparecidos de todo el país. }\end{array}$ \\
\hline $\begin{array}{l}\text { Resultados } \\
\text { Externos }\end{array}$ & $\begin{array}{l}\text { Reconocimiento legal de las víctimas de derechos humanos. Socialización } \\
\text { y visibilidad de la crisis de desaparición forzada y de derechos humanos. } \\
\text { Creación de mecanismos estatales de atención a familiares de víctimas de } \\
\text { desaparición forzada. Ley de Desaparecidos. }\end{array}$ \\
\hline
\end{tabular}

Fuente: Elaboración propia 
Como hemos visto hasta aquí, los colectivos de mujeres creados en todo el país en medio de la actual crisis de derechos humanos, se han convertido en un referente local para la articulación de las víctimas, motivando la denuncia y documentación de sus casos, la construcción de redes de apoyo ${ }^{6}$, exigencia de justicia y rendición de cuentas, pasando de víctimas a activistas y construyendo capacidades para la defensa de los derechos humanos.

\section{Conclusiones}

Hasta ahora las agendas sobre violencia y acción colectiva de las mujeres están fragmentadas y disociadas de los estudios sobre seguridad y crimen organizado en México. En este capítulo he demostrado que la actual crisis de derechos humanos afecta a las mujeres en dos sentidos diversos: en una primera parte, analicé la situación de los derechos de las mujeres en el país en el contexto de conflictos armados por la actuación de organizaciones criminales y las fuerzas de seguridad en todo el territorio nacional. Expuse la necesidad de avanzar en la caracterización de las graves violaciones de los derechos humanos de las mujeres en un marco estructural de conflicto armado. Del mismo modo, evidencié las consecuencias de invisibilizar este fenómeno en su integralidad -la escalada de la violencia de género y las graves violaciones de los derechos humanos de las mujeres en una situación de conflicto armado creada por las actividades de las organizaciones criminales y la falta de respuesta del Estado-, lo que ha impedido su prevención, documentación, transformación y resolución, favoreciendo la impunidad de los crímenes cometidos.

En una segunda parte, expliqué cómo las mujeres víctimas directas e indirectas en este contexto de conflicto armado y graves violaciones de

6 Las iniciativas locales de colectivos de familiares se están articulando con organizaciones no gubernamentales de carácter nacional al conformar, a finales del 2015, el Movimiento por Nuestros Desaparecidos en México, donde participan todas las iniciativas locales antes mencionadas y muchas otras compuestas también, en su gran mayoría, por mujeres. En 2016 lanzaron la campaña \#SinLasFamiliasNo la cual busca exigir una Ley General sobre Desaparición Forzada y por Particulares que incluya, entre otras cosas, la experiencia de las familias así como su participación activa en la elaboración y seguimiento de las políticas públicas en la materia. Al respecto ver su página web. 
derechos humanos, están teniendo un papel fundamental en las regiones y localidades para promover acciones colectivas en torno a los derechos humanos. Un rasgo importante de la acción colectiva es que es llevada a cabo por mujeres sin experticia profesional en el campo de defensa de los derechos humanos, esta construcción de capacidades ha contribuido a ampliar el conocimiento de los derechos humanos en amplios y nuevos colectivos sociales. La movilización sostenida de las mujeres en diferentes áreas de actuación, ha logrado hacer visibles la crisis de derechos humanos en el país, movilizando su dolor particular han logrado construir una visión de los derechos humanos como marco de acción colectiva que nos implica a todos y, a la vez, a todos nos trasciende. Mujeres en todo el país están encabezando acciones colectivas que se están apropiando de los derechos humanos como recursos de movilización, extendiendo el lenguaje de derechos en amplios colectivos sociales para su reivindicación, creando redes de apoyo y presión, denunciando la violencia de las organizaciones criminales y su connivencia con autoridades estatales, así como buscando la interlocución con los gobiernos para el diseño de políticas públicas que garanticen el respeto de los derechos humanos.

\section{Referencias}

Aikin, O. (2011) Activismo social trasnacional: un análisis en torno a los feminicidios en Ciudad Juárez. México: Instituto Tecnológico y de Estudios Superiores de Occidente, El Colegio de la Frontera Norte \& Universidad Autónoma de Ciudad Juárez.

Álvarez, R. M., \& Pérez, A. (Coord.). (2010). Modelos para prevenir, atender, sancionar y erradicar la violencia contra las mujeres. México: Instituto de Investigaciones Jurídicas-Universidad Nacional Autónoma de México \& Consejo Nacional de Ciencia y Tecnología.

Anaya, A. (2012). El país bajo presión. Debatiendo el papel del escrutinio internacional de derechos humanos sobre México. México: CIDE.

Amnesty International. (2016). Surviving death. Police and military torture of women in Mexico. Londres: Amnesty International.

Amnesty International. (2015). Paper promises, daily impunity: Mexico's torture epidemic. Londres: Amnesty International. 
Barrios, D. (24 de junio de 2013). Madres de desaparecidas en Juárez contra la ineptitud del gobierno. DesInformémonos. Recuperado de https://desinformemonos.org/madres-de-desaparecidas-en-juarez-contra-la-ineptituddel-gobierno/

Bates, R. (2008). State Failure. Annual Review of Political Science, 11, 1-12.

Beittel, J. (2015) Mexico: Organized Crime and Drug Trafficking Organizations. Washington: Congressional Research Service.

Berber, M. A. (1 de julio de 2016). Trayectorias de violencia. Homicidios 20082014. Nexos. Recuperado de http://www.nexos.com.mx/?p=28803

Carrasco, J. (10 de junio de 2010). Familiares de víctimas del narco en Sinaloa se manifiestan en el DF. Proceso. Recuperado de http://www.proceso.com. $\mathrm{mx} / 100273 /$ familiares-de-victimas-del-narco-en-sinaloa-se-manifiestan-en-el-df

Castañeda, M. P., Ravelo, P., \& Pérez, T. (2013). Feminicidio y violencia de género en México: omisiones del Estado y exigencia civil de justicia. Iztapalapa Revista de Ciencias Sociales y Humanidades, 34(74), 11-39.

Cervantes, M. T. (2015). La participación social en familias víctimas de desaparición involuntaria. RISCH Revista Iberoamericana de las Ciencias Sociales y Humanísticas, 4(8), 48-59.

Cobo, R. (2011). Hacia una nueva política sexual. Las mujeres ante la reacción patriarcal. Madrid: Los Libros de la Catarata.

Collier, P., \& Hoeffler, A. (2004). Greed and grievance in civil war. Oxford Economic Papers, 56(4), 563-595.

Corcoran, P. (4 de agosto de 2011). Mexico: Upstart Gangs Eat into Cartel Hegemony. In Sight: Organized Crime in the Americas. Recuperado de http://www. insightcrime.org/news-analysis/mexico-upstart-gangs-eat-into-cartel-hegemony

Coria, C. (16 de enero de 2013). Madres de desaparecidas caminan de Ciudad Juárez a Chihuahua. Excelsior. Recuperado de http://www.excelsior.com. $\mathrm{mx} / 2013 / 01 / 16 / 879692$

Corte Interamericana de Derechos Humanos. (2009). Caso González y otras ("Campo Algodonero") c. México. Excepción Preliminar, Fondo, Reparaciones y Costas. Sentencia del 16 de noviembre de 2009. Serie C No. 205.

Comisión Interamericana de Derechos Humanos. (2015) Situación de derechos humanos en México, OEA/Ser.L/V/II, Doc 44/15, Washington, DC: Organización de Estados Americanos.

Comisión Intersecretarial. (2014). Informe anual 2013. México: SEGOB.

Comisión Intersecretarial. (2014). Programa Nacional para Prevenir, Sancionar y Erradicar los Delitos en Materia de Trata de Personas y para la Protección y Asistencia a las Víctimas de estos Delitos 2014-2018. México: SEGOB. 
Comité para la Eliminación de la Discriminación contra la Mujer, CEDAW. (2012). Observaciones finales del Comité para la Eliminación de la Discriminación contra la Mujer, México. Nueva York: Naciones Unidas.

David, S. (1 997). Internal War: Causes and Cures. World Politics, 49(4), 552-576.

Departament of State. (2016). Trafficking in Persons Report 2016. Washington:

Departamento de Estado. Recuperado de https://www.state.gov/j/tip/rls/ tiprpt/2016/

Dorff, R. (2005). Failed States After 9/11: What Did We Know and What Have We Learned? International Studies Perspectives, 6(1), 20-34.

Echarri, C. J. (2016). La violencia feminicida en México, aproximaciones y tendencias 1984-2014. México: SEGOB, Secretaría de Gobernación, INMUJERES, Instituto Nacional de las Mujeres, ONU Mujeres \& Entidad de las Naciones Unidas para la Igualdad de Género y el Empoderamiento de las Mujeres.

Eriksson, M., \& Wallensteen, P. (2004). Armed Conflict, 1989-2003. Journal of Peace Research, 41(5), 625-636.

Escalante, F. (1 de enero de 2011). Homicidios 2008-2009. La muerte tiene permiso. Nexos.

Excelsior (Redacción). (16 de julio de 2015). Feminicidios evidencian pornografía sádica en Juárez: estudio. Excelsior. Recuperado de http://www.excelsior. com.mx/nacional/2015/07/16/1035059

Fearon, J., E Laitin, D. (2003). Ethnicity, Insurgency, and Civil War. American Political Science Review, 97(1), 75-90.

Finklea, K. M, et ál. (2010). Southwest Border Violence: Issues in Identifying and Measuring Spillover Violence. Washington: Congressional Research Service. Recuperado de: http://digitalcommons.ilr.cornell.edu/key_workplace/767

Flores, R. (30 de julio de 2014). Se dedican a la trata 47 grupos criminales. Excelsior. Recuperado de http://www.excelsior.com.mx/nacional/2014/07/30/973599

Flores, R. \& Reyes, J. (15 de abril de 2016). Sedena admite caso de tortura en Guerrero; la PGR investiga abusos. Excelsior. Recuperado de http://www. excelsior.com.mx/nacional/2016/04/15/1086591

García, J. L., E Padilla, A. (24 de abril de 2016). \#VivasNosQueremos: Mujeres marchan en al menos 10 entidades contra la violencia machista. Sin embargo.mx. Recuperado de http://www.sinembargo.mx/24-04-2016/1652394

Grayson, G., G Logan, S. (2012). The Executioner's Men: Los Zetas, Rogue Soldiers, Criminal Entrepreneurs, and the Shadow State They Created. New Jersey: Transaction Publishers.

Guerrero, E. (1 de junio de 2011). La Raíz de La Violencia. Nexos, 402. Recuperado de http://www.nexos.com.mx/?p=14318 
Gurney, K. (31 de julio de 2014). Red de trata de personas en México revela cambio en el papel de los carteles. InSight Crime. Centro de Investigación de Crimen Organizado. Recuperado de http://es.insightcrime.org/component/ tags/tag/211-trata-de-personas?limit=10Estart=30

Hegre, H., E Sambanis, N. (2006). Sensitivity Analysis of Empirical Results on Civil War Onset. Journal of Conflict Resolution, 50, 508-535.

Heras, A. (24 de octubre de 2015). Critican a alcalde de Tijuana por promover el turismo sexual. La Jornada Baja California. Recuperado de http://jornadabc.mx/tijuana/24-10-2015/critican-alcalde-de-tijuana-por-promover-elturismo-sexual

Hernández, E. (2015). Tierra de padrotes: Tenancingo, Tlaxcala, un velo de impunidad. México: Tusquets Editores.

Hincapié, S. (2015). Estado y crisis de derechos humanos en México México. Claves analíticas para su interpretación. El Cotidiano, 193, 89-96.

Hincapié, S., E López, J. (2016). Ciclos de movilización y crisis de derechos humanos. La acción colectiva de las ONG nacionales y los derechos humanos en México. Revista de Estudios Sociales, 56, 26-38.

Hunt, L. (2009). La invención de los derechos humanos. Barcelona: Tusquets.

Jasper, J. (2014). Constructing Indignation: Anger Dynamics in Protest Movements. Emotion Review, 6(3), 208-213.

Jasper, J. (2012). ¿De la estructura a la acción? La teoría de los movimientos sociales después de los grandes paradigmas. Sociológica, 27(75), 7-48.

Kaldor, M. (2001). Las nuevas guerras: la violencia organizada en la era global. Barcelona: Tusquets.

Kalyvas, S. (2001). New and Old Civil Wars: A Valid Distinction? World Politics, 54(1), 99-118.

Kalyvas, S. (2003). The Ontology of 'Political Violence': Action and Identity in Civil Wars. Perspectives on Politics, 1(3), 475-494.

Kalyvas, S. (2006). The Logic of Violence in Civil War. Cambridge: Cambridge University Press.

Keck, M., E Sikkink, K. (2000). Activistas sin fronteras. Redes de defensa en politica internacional. México: Siglo XXI Editores.

Lagarde, M. (2011). Prefacio: claves feministas en torno al feminicidio. Construcción teórica, política y jurídica. En R. Fregoso (Coord.), Feminicidio en América Latina (pp. 11-41). México: Centro de Investigaciones Interdisciplinarias en Ciencias y Humanidades (CEIICH)-UNAM \& Red de Investigadoras por la Vida y la Libertad de las Mujeres (Diversidad Feminista).

Landmann, T. (2006). Studying Human Rights. Nueva York: Routledge. 
León, M. A. (2 de julio de 2016). Los feminicidios con Duarte aumentan a 509: la impunidad los alienta, acusa académica de la UV. Sinembargo.mx. Recuperado de http://www.sinembargo.mx/02-07-2016/3061849

López, J., E Hincapié, S. (2015). Campos de acción colectiva y las ONG de derechos humanos. Herramientas teóricas para su análisis. Sociológica, 30(85), 9-37.

McAdam, D., McCarthy, J., \& Zald, M. (2006). Comparative Perspectives on Social Movements: Political Opportunities, Mobilizing Structures, and Culture Framings. Nueva York: Cambridge University Press.

Manjarrés, A. (21 de enero de 2013). El silencio que reclama justicia. El Universal. Recuperado de http://www.noroeste.com.mx/publicaciones.php?id=841539

Martín, A., Fernández, A., E Villerreal, K. (2008). Activismo transnacional y calidad de la democracia en México: Reflexiones en torno al caso de Ciudad Juárez. ERLACS, (84), 21-36. DOI: http://doi.org/10.18352/erlacs.9624

Martínez, L. (14 de abril de 2016). Torturan militares y federales a una mujer. SDPnoticias.com. Recuperado de http://www.sdpnoticias.com/nacional/2016/04/14/torturan-militares-y-federales-a-una-mujer-video

Martínez, D. (8 de marzo de 2016). Alerta de Género: una esperanza aún lejana para las mujeres. Expansión. Recuperado de http://expansion.mx/economia/2016/03/08/alerta-de-genero-una-esperanza-contra-los-feminicidios

Méndez, J. E. (2014). Report of the United Nations Special Rapporteur on torture and other cruel, inhuman, or degrading treatment or punishment. Mission to Mexico. Nueva York: United Nations Human Rights Council.

México, Congreso General de los Estados Unidos Mexicanos. Ley General de Acceso de las Mujeres a una Vida Libre de Violencia (1 de febrero de 2007).

Olvera, D. (10 de mayo de 2016). Madres toman las calles en 5 estados y la CdMx para reclamar por sus hijos desaparecidos. Sinembargo.mx. Recuperado de http://www.sinembargo.mx/10-05-2016/1658703

Open Society Justice Initiative. (2016). Atrocidades innegables: Confrontando crímenes de lesa humanidad en México. Nueva York: Open Society Foundations. ONU Mujeres. (9 de marzo de 2017). Toman las calles en América Latina y el Caribe por el Día Internacional de la Mujer. Recuperado de http://lac. unwomen.org/es/noticias-y-eventos/articulos/2017/03/dia-internacionalde-la-mujer-onu-mujeres-regional

Rincón, S. (14 de marzo de 2017). Familiares de desaparecidos encuentran en México la fosa clandestina 'más grande del mundo'. Univisión noticias. Recuperado de http://www.univision.com/noticias/america-latina/familiares-de-desaparecidos-encuentran-en-mexico-la-fosa-clandestina-mas-grande-del-mundo 
Risse, T., Ropp, S., \& Kathryn, S. (2013). The persistent power of human rights: from commitment to compliance. Cambridge: Cambridge University Press.

Risse, T., Ropp, S., \& Kathryn, S. (1999). The power of human rights: international norms and domestic change. Cambridge: Cambridge University Press.

Robledo, C. (2015). El laberinto de las sombras: desaparecer en el marco de la guerra contra las drogas. Estudios Políticos, 47, 89-108. DOI: 10.17533/ udea.espo.n47a06

Román, J. A. (2 de diciembre de 2015). Ordena jueza al Estado mexicano ofrecer disculpas por feminicidios. La Jornada. Recuperado de http://www.jornada. unam.mx/ultimas/2015/12/02/ordena-jueza-al-edomex-ofrecer-disculpaspor-feminicidios-270.html

Rosagel, S. (26 de marzo de 2016). La lista de estados donde ser mujer es un riesgo crece, y los gobiernos no oyen, dicen ONGs. Vanguardia. Recuperado de http://www.vanguardia.com.mx/articulo/la-lista-de-estados-donde-sermujer-es-un-riesgo-crece-y-los-gobiernos-no-oyen-dicen-ongs

Russell, D., E Radford, J. (Eds.) (2006). Feminicidio. La politica del asesinato de las mujeres. México: CEIICH -UNAM.

Sagot, M., E Carcedo, A. (2011). Cuando la violencia contra las mujeres mata: femicidio em Costa Rica, 1990-1999. En R. Fregoso (Coord.), Feminicidio en América Latina. (pp. 193-220). México: Centro de Investigaciones Interdisciplinarias en Ciencias y Humanidades -UNAM \& Red de Investigadoras por la Vida y la Libertad de las Mujeres (Diversidad Feminista).

Sambanis, N. (2004). What Is Civil War? Conceptual and Empirical Complexities of an Operational Definition. The Journal of Conflict Resolutions. 48(6), 814-858.

Schedler, A. (2016). En la niebla de la guerra. Los ciudadanos ante la violencia criminal organizada. México: CIDE.

Shaw, M. (1999). War and Globality: the Role and Character of War in the Global Transition. En J. Ho-Won (Ed.), Peace and Conflict: A New Agenda. (pp. 61-80). Hampshire: Ashgate Publishing.

Segato, R. L. (2006). Que es un feminicidio. Notas para un debate emergente. Mora, 12, 3-18.

Sen, A. (2010). La idea de la justicia. México: Taurus.

Sikkink, K. (2014). Latin American Countries as Norm Protagonists of the Idea of International Human Rights. Global Governance, 20(3), 389-404.

SinEmbargo.mx (Redacción). (26 de mayo de 2016). Madres que decidieron buscar a sus hijos por su cuenta viven acoso y amenazas en Veracruz. SinEmbargo.mx. Recuperado de http://www.sinembargo.mx/09-05-2016/1658290 
Simmons, B. (2009). Mobilizing for Human Rights: International Law in Domestic Politics. Cambridge: Cambridge University Press.

Sosa, M. (20 de octubre de 2016). América Latina grita 'Ni una menos': las protestas contra los feminicidos toman las capitales. Univisión noticias. Recuperado de http://www.univision.com/noticias/violaciones/america-latinagrita-ni-una-menos-las-protestas-contra-los-feminicidios-toman-las-capitales

Stammers, N. (2009). Human rights and social movements. London: Pluto Press.

Tarrow, S. (2009). El poder en movimiento. Los movimientos sociales, la acción colectiva y la politica. Madrid: Alianza.

Tavera, P. (Coord.) (2015). Sobreviviendo al riesgo. Personas defensoras de derechos humanos y sus organizaciones. México: Centro de Investigación y Capacitación Propuesta Cívica.

Tercero, M. (junio de 2010). Culiacán, el lugar equivocado. Letras Libres, 54-62. Recuperado de http://www.letraslibres.com/mexico-espana/culiacan-ellugar-equivocado

Tilly, C. (2004). ¿De dónde vienen los derechos? Sociológica, 55(19), 273-300.

Tilly, C., E Wood, L., (2010). Los movimientos sociales, 1768-2008. Desde sus orígenes hasta Facebook. Barcelona: Critica.

Tsutsui, K., Whitlinger, C., \& Alwyn, L. (2012). International Human Rights Law and Social Movements: States' Resistance and Civil Society's Insistence. Annual Review of Law and Social Science, 8, 367-396.

Van Creveld, M. (1991). The Transformations of War. Nueva York: The Free Press.

Vázquez, D., E Estévez, A. (2010). Los derechos humanos y las ciencias sociales. Una perspectiva multidisciplinaria. México: FLACSO \& CISAN-UNAM.

Villarreal, M. T. (2014). Respuestas ciudadanas ante la desaparición de personas en México (2000-2013). Espacios Públicos, 17(39), 105-135.

Villela, G. (2 de septiembre de 2016). Obstaculizan la Alerta de Violencia de Género como si se atacara a los gobiernos. Cimacnoticias. Recuperado de http://www.cimacnoticias.com.mx/noticia/obstaculizan-alerta-de-violenciade-g-nero-como-si-se-atacara-los-gobiernos

Waldmann, P., \& Reinares, F. (Comps.) (1999). Sociedades en guerra civil. Conflictos violentos de Europa y América Latina. Barcelona: Paidós.

Waldmann, P. (2012). El narcotráfico en México: Una escalada de violencia anónima.. Puebla: Universidad Benemérita de Puebla, Instituto de Ciencias de Gobierno y Desarrollo Estratégico. Documento de Trabajo 3.

Zavaleta, N. (28 de enero de 2017). Sinaloa: La incansable búsqueda de desaparecidos. Proceso. Recuperado de http://www.proceso.com.mx/472199/ sinaloa-la-incansable-busqueda-desaparecidos 